\title{
Kürtçe İsim Tamlamasının Yapısı ${ }^{1}$
}

\section{Jan Strunk}

Çev.: Hasan Karacan² ${ }^{2}$ M. Veysi Babayiğit ${ }^{3}$

Received: November 1, $2015 \quad$ Accepted: December 15, 2015

\section{GIRIȘ}

Kürtçe; Ermenistan, Azerbaycan, İran, Irak, Suriye ve Türkiye'de konuşulan bir Hintİran dilidir. Bazen farklı diller olarak kabul edilen birkaç lehçeye ayrılmaktadır. Bu rapor sözcük işlevi, dil bilgisi (Lexical Functional Grammar) çerçevesi içinde Kürtçe isim tamlamasının analizini amaçlamaktadır. Özellikle Kurmanci diye adlandırılan Kürtçe lehçesindeki isim tamlaması üzerinde durulacaktır. Bu raporda kullanılan veri; Türkiye'de Muş'un yerli lehçesiyle Almanya'nın Bochum Üniversitesinde gerçekleştirilen kayıtlardan ve raporlardan alınmıştır. İkinci bir kaynak olarak, Alman konuşmacıları için Kurmanci'ye Giriş konulu kitabı olan Wurzel'den (1997) cümleler alıntılanmıştır.

\section{GENEL BAKIŞ}

Kurmanci’deki sembolik tamlamanın doğrusal yapısı şekilde gösterilmiştir.(1)

(1) DEM Num/Qnt $\quad \mathrm{N} \quad \operatorname{Prn}(\mathrm{OBL}) \quad \mathrm{AP}, \mathrm{NP}(\mathrm{OBL}) \quad \mathrm{PP}$

Bir isim tamlaması en az bir önaddan oluşur. Örnek (2)

(2) gul sor $=e$.

flower red=be.2/3.SG.PRES

'The flower is red.'

' Çiçek kırmızıdır.'

Recommended citation:

Karacan, H. \& Babayigit, M. V. (2016). Kürtçe İsim Tamlamasının Yapısı [The Structure of the Kurdish

Noun Phrase, Jan Strunk, December 15, 2003]. International Journal of Kurdish Studies 2 (1), pp. $29-50$.

\footnotetext{
${ }^{1}$ Bu makale 15 Aralık 2003 tarihinde Jan Strunk tarafindan hazırlanan “The Structure of the Kurdish Noun Phrase" adlı çalışmasının tercümesidir.

${ }^{2}$ Asst. Prof. Dr., Department of Kurdish Language and Culture, Dicle University, hasan.karacan@dicle.edu.tr

${ }^{3}$ MA Student, Department of Kurdish Language and Culture,Dicle University, Diyarbakır, Turkey
} 
Diğer öğeler ve sözcük grupları, asıl ismin sağında ya da solunda görülebilir. Bölüm 3 asıl ismin solunda görünen öğelerle ilgilidir. Bölüm 4 Kurmanci'de ilginç öğelere sahip olan sağa doğru olan değişikliği tartışmaktadır.

\section{NOMINAL ÖNCESİ ÖĞELER}

Kurmanci'de iki tane nominal öncesi durum var. İşaret zamirleri daima nominal bir gösterimde sol tarafta bulunur. Örneğin (3)'de, bu raporda, nominal işlevsel gösterimdeki DP (aitlik sözcüğü) başında olduklarını ve belirteç kategorisini gösterdikleri ele alınacaktır. İşaret zamirlerin, zamir olarak kullanabilmesinin bir nedeni var ve bu da bir işaret zamiri olmadan isim tamlamasının oluşumu ya da isim tamlamalarını içeren DPs gibi aynı dağılıma sahiptir.

(3) a. [DP va mer-a] di-bêj-e

$\begin{array}{rrr}\text { DEM.SG.NOM } & \text { man-NOM } & \text { DUR-say.PRS-2/3.SG } \\ \text { (tekil) } & \text { adam } & \text { demek. }\end{array}$

'This man says...' ‘ Bu adam diyor $[\mathrm{ki}]$...'

b. $E z \quad[D P v i \quad$ jin-ê] di-bîn-im

$\begin{array}{rrcc}\text { 1.SG.NOM } & \text { DEM.SG.OBL } & \text { woman-OBL } & \text { DUR-see.PRS-1.SG } \\ \text { (tekil) ben } & (\text { tekil belirteç) } & \text { kadın } & \text { görmek } \\ & \text { 'I see this woman.' ' Bu kadını görüyorum.' }\end{array}$

(4) $v a \quad r a-d i-b-i$

DEM.SG.NOM up-DUR-be.PRS-2/3.SG

(tekil belirteç) (uyanmak)

'This (the girl) gets up.' ' $\mathrm{Bu}(\mathrm{k} 1 \mathrm{z})$ uyanıyor.'

Asıl isimden önce olan ikinci bir tür öğeler başlıca birkaç sayı ve gişt (hepsi), herdu (ikisi) gibi diğer belirteçlerdir. Bunlar işaret zamirlerinden sonra gelirler. Örneğin, örnek(5) de ve bu yüzden bir DP'de yardımcı ad olarak yerleştirilen bir sayı sözcüğü tamlamasının başında oldukları ele alınacaktır. Aksine sıra sayıları baştaki ismi takip etmek zorunda olan düzenli bir sıfat olarak görülebilir.

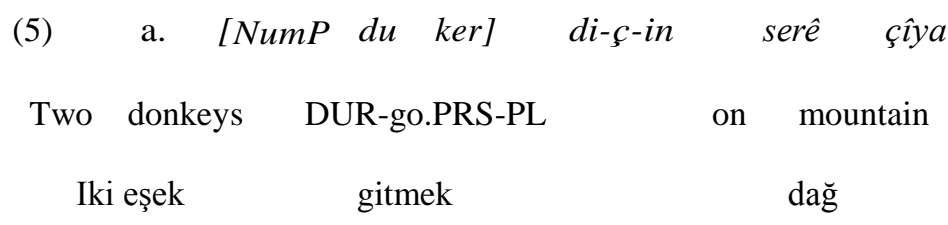


'Two donkeys go on the mountain.' ' İki eşek dağa gidiyor.'

$\begin{array}{lcc}\text { b. Va } & \text { gişt } & \text { kitêb-an } \\ \text { DEM.PL } & \text { all } & \text { book-PL } \\ \text { (Çoğul) } \quad \text { (tüm) } & \text { (kitap) } \\ \text { 'all these books' } & \text { 'tüm bu kitaplar' }\end{array}$

Nominal öğelerin gruplaşmasını açıklamak için sonraki yapı kurallarına çözüm getirilecektir.

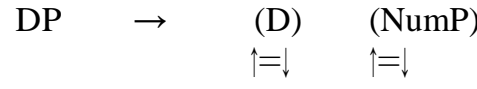

$$
\begin{aligned}
& \text { NumP } \rightarrow \text { (Num) (NP) } \\
& \uparrow=\downarrow \quad \uparrow=\downarrow
\end{aligned}
$$

İleri gramer kurallarını yazarak basitleştirmek ve bir cümlede isim tamlamalarının (NPs) ve aitlik öbeklerinin ( DPs) aynı dağılıma sahip olduğunu yakalamak için bu sözcüklerin önadları oluşturulacaktır.

Aşağıdaki 'vi' belirteci için örnek sözcük girişidir.

$$
\begin{aligned}
\text { vi } \quad \text { D } \quad & \left((\uparrow \mathrm{PRED})={ }^{\prime} \mathrm{PRO}{ }^{\prime}\right) \\
& (\uparrow \mathrm{DEF})=+ \\
& (\uparrow \mathrm{CASE})=\mathrm{OBL} \\
& (\uparrow \mathrm{NUM})=\mathrm{SG}
\end{aligned}
$$

Bresnan (2001) uygulamasına göre, düzenli şahıs zamirleri de belirteçlerin bir öğesi olduğu varsayılır. Zamirlerin bağlı (izafe) bir isim tamlamasına belirteç olarak rol alıp almadığı belirlenmek zorundadır. Eğer yapılamıyorsa, yukarıdaki 'vi' sözcük girişindeki belirteçlerin aksine yüklem özelliği seçeneksiz olmak zorundadır. 


\section{NOMINAL SONRASI DEĞİŞIM}

Tüm Aitlik öbekleri (DPs), Sıfat Öbekleri (APs) ve Edat Öbeklerini (PPs) değiştiren bir ismi takip etmek zorundadır ${ }^{4}$. Aitlik öbekleri daima dolaylı durumda olmak zorundadır. Genellikle direkt olarak önadı takip ederler. Bu durum aitlik zamirleri için zorunlu iken, daha anlamlı aitlik öbekleri, sıfat öbeklerinden önce gelebilir. Edat öbekleri sadece isim tamlamalarının sağında bulunur. Çok nadiren edat tamlayanı ile karşılaşıldı dolayısıyla farklı edat öbeklerin tek bir adı değiştireceği kesin değildir. İngilizcenin aksine, belirtili ve aitlik öbekleri tamamen dil bilgisel olsun diye birbirini dişlamaz. Böylece belirteçler ve aitlik öbekleri ne yer olarak ne de işlevsel olarak tamamlayıcı dağılımda değildirler.

$$
\begin{array}{lcc}
\text { wa } & \multicolumn{1}{c}{\text { jin-ên }} & \text { bir }=\hat{e} n \\
\text { DEM.PL } & \text { wife-EZ.PL brother=EZ.PL } \\
\text { (belirteç-çoğul) } & \text { eş-çoğul erkek kardeş - çoğul } \\
& \text { 'those her sisters-in-law' } \\
& \text { 'Şunlar onun yengeleri' }
\end{array}
$$

wi

3.SG.OBL

(nesne)

Kürtçedeki en ilginç durum ( ve de diğer Kürt lehçelerinde) bu çalışmada EZ olarak yorumlanan 'ezafe' ya da 'izafe' dir. ${ }^{5}$ Bir Sifat Öbeği, Aitlik öbeği hatta bir edat öbeğinde değişmiş ya da nominal sonrası değişen adlar arasında görünen bir tür bağlayıcı morfemdir. ${ }^{6}$ Bu morfem cinsiyet ve sayı açısından önad ile uyuşur ( Dişil tekil : -a, Eril tekil : -e ve Çoğul : -en) 'dir. Aşağıdaki örnekleri inceleyiniz:

$$
\begin{aligned}
& \text { a. mal-a [DP min] } \\
& \text { house-EZ.FEM.SG 1.SG.OBL } \\
& \text { ev (1.tekil şahıs) } \\
& \text { 'my house' / ' benim evim' } \\
& \text { b. mal-a [AP sor] } \\
& \text { house-EZ.FEM.SG red }
\end{aligned}
$$

\footnotetext{
${ }^{4}$ Belirteçlerin ve tamlayanların önemli bir durumda farklı davranıp davramadığla ilgili henüz kesinlik yoktur. Ek çalışmalar bu olasılığı incelemelidir.

${ }^{5} \mathrm{Bu}$ durum aynı zamanda Farsça'da da görülür. Örneğin Kahnemuyipour (2000) bu konuyla ilgili son çalışmasıdır. Farklı Kürt lehçelerindeki izafe'nin genel tanımı McKenzi'de (1961) bulunabilir.

${ }^{6} \mathrm{Bu}$ yazının geri kalanında, izafe işaretleyicisinin önad'da göründüğünde bir ek; iki değiştirici sözcük arasında göründüğünde ise klitik olduğunu tartışılacaktır.
} 


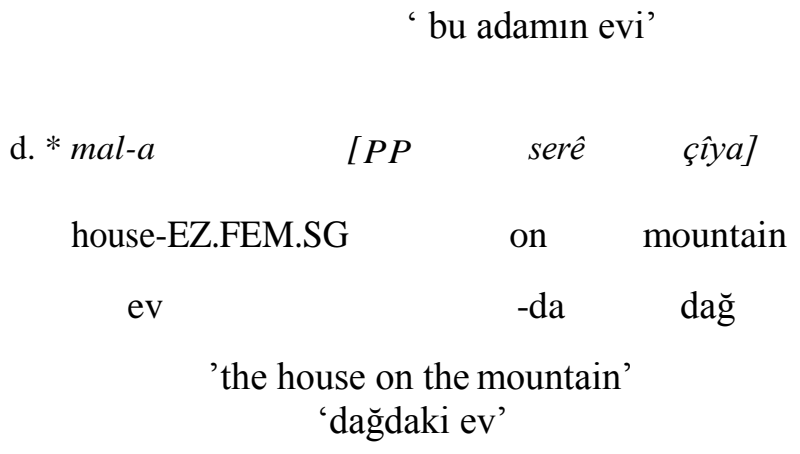

İzafe işaretleyicisi önad 'a sınırlanmamıştır. Önad'ın diğer değiştiricisi tarafından takip edilen her öğe, bir izafe işaretçisinin diğer önadla uyuştuğunu gösterir.

(9)
a. mal-a
house-EZ.FEM.SG
'my red house'
benim kırmızı evim'
b. mal-a
house-EZ.FEM.SG
$m e \hat{r}-\hat{e}]$
man-SG.OBL
'this man's red house'
'bu adamın kırmızı evi'

$\begin{array}{llr}{[D P \quad \min ]=a} & {[A P} & \text { sor }] \\ \text { my=EZ.FEM.SG } & \text { red }\end{array}$

$\begin{array}{lll}{\left[A P \quad \begin{array}{l}\text { sor }]=a \\ \text { red=EZ.FEM.SG }\end{array}\right.} & {[N P \quad v \hat{\imath} \quad \text { DEM.SG.OBL }}\end{array}$

Temel olarak, nominal sonrası değişimler izafe morfemiyle işaretlidir ${ }^{7}$; Sadece en sağdaki ek değiştirici takip etmediğinden ve direk bağlaca ihtiyaç olmadığından izafe işaretleyicisi taşımaz.

Şimdiye kadar izafe morfemini önad üzerinde bir ek ama değiştiriciler üzerinde ise klitik olarak yorumlanmıştır. İzafe'yi önadın bir parçası; ancak iki değiştirici arasındaki izafe morfemlerini bağımsız parçalar olarak gören Kürt imla uygulaması takip edilmiştir. İlk analize başlamadan önce, izafe birleşimine bakılmasında yarar vardır. Önceki öğeyle mi ya da sonraki öğeyle mi birleşim oluşturur? Veya aslında önceki ile sonraki öğeler arasında mı durur? Eğer izafe önad üzerinde gerçekten bir ek ise, sözcük bütünlüğü ilkesine saygı duymak istiyorsak onu değiştirilmiş bir adla birleşim (sublexical) oluşturduğunu sonradan kesinlikle kabul etmek zorundayız. Ancak, diğer tartışmalar; ( iki değiştirici arasında bulunan en az birini) izafe'yi ne önceki ne de sonraki birleşim olarak tanımışlardır ama aslında ikisini birleştiren ve aralarında duran sonuçlara varmışlardır. Öncelikle, onu önceki değiştirici

\footnotetext{
${ }^{7}$ İzafe işaretleyicilerinin bulunmadığı bazı ekleme yapıları vardır. Bu çalışmada bu tür yapılara değinilmeyecektir.
} 
üzerinde bir ek olarak düşünülürse belki de İngilizcenin 'in' haliyle karşılaştırıldığında (örneğin klitik) gibi deyimsel bir ek olarak benimsenmesi gerekmektedir. Çünkü önceki kelimenin hangi kelime grubuna ait olduğunu gözetmeksizin daima önceki değiştiricinin sağında görünmektedir.

(9a) örneğinde bir zamiri, (9b)'de bir sıfatı ve önadı değiştiren bir sözcügün sağ kenarında bulunan herhangi bir kelimeye uyan ilkeyi takip eder. İkinci , (10) örnekte de görüldüğü gibi, iyelik yapıdaki ekler kendilerini değiştirebilirler ancak tüm iyeliği takip eden izafe önadla uyuşmak zorunda çünkü bu durumda sıfat öbeklerini, belirteçleri birbirine bağlar.

a. mal-a

house-EZ.FEM.SG

ev bira $=y \hat{e}$

brother=EZ.MASC.SG

erkek kardeş $\min =a$

piçûk

'my brother's small house'

'Benim kardeşimin küçük evi'

b. mal-a

house-EZ.FEM.SG bira $=y \hat{e}$

brother=EZ.MASC.SG

ev erkek kardeş benim küçük

'my small brother's house'

'Benim küçük kardeşimin evi'

Üçüncüsü, izafe sadece önadın bağıl ekinden önce oluşur örneğin bu oluşum sonraki kelimeye bağlıdır. Ayrıca Wurzel (1997) tarafından kesin izafe denilen bir olgu vardır. Bu İngilizcedeki tek zamirlilerle karşılaştırılabilinen bir yapıdır örneğin "a green one- yeşil olan", "these big ones- bu büyük olanlar" gibi. Bir izafe morfemi ve onu takip eden bir belirteç ya da iyelik içerir ancak belli bir önad içermez. Örneğin;

a. ya

$\min$

\title{
EZ.FEM.SG 1.SG.OBL \\ 'mine' (feminine) ( benimki)
}

Wurzel 1997:25)

\author{
b. nav-ê \\ $y \hat{e}$ \\ mezin \\ name-EZ.MASC.SG EZ.MASC.SG big \\ 'the big one's name' 'büyük olanın adı' (Wurzel 1997:31)
}


Son iki görüş, izafe yi değiştirici sözcüğün bir parçası olarak sayan analiz için kanıt olarak sayılabilir. Ancak izafe morfeminin değiştirici sözcüğün bir parçası olmadığ 1 düşünülmektedir. Çünkü sadece bir isim öbeğinin içinde oluşur ve asla görünmeyen bir önadı ima etmeksizin bir sıfat öbeği, aitlik öbeği ya da edat öbeğiyle yüklem olarak kullanıldığında değildir. Karşılaştırıcı bağlayıcı morfem e sahip olan Arnavutça ya zıttır ( Himmelmann 1997:chapter 5). Kürt izafenin aksine, bu morfem sadece belirli sıfat gurupları ve aitlik zamirleriyle görünür ve böylece sözcüksel olarak şartlanır. Ayrıca yüklem olarak kullanıldığında, sıfatlardan önce de gelir.

Örneğin:

$$
\text { vajz-a }
$$

eshtë

$$
e
$$

bukur

girl-DEF.NOM.SG.FEM be.3.SG.PRES LK.NOM.SG.FEM pretty

k1z dir güzel

'the girl is pretty' 8

'Kız güzeldir'(Himmelmann 1997:chapter 5, example 23)

Böylece, bu çalışmanın geri kalanında izafe yapısı için sonraki yapı analizi ele alınacaktır.

$$
[N P \quad[N \quad \mathrm{X}] \mathrm{EZ}[A D J / P O S S \quad \mathrm{Y}]]
$$

\subsection{Birinci Analiz.}

LFG analizinin birinci taslağına çözüm getirmek için bu bölümde Kürtçe 'deki imla çalışmasının aksine baştaki isimdeki izafenin de bir sonek değil basit bir klitik olduğuna değineceğim ve bir seçenek sunacağım. Fakat 4.2. bölümdeki analizinden daha karmaşıktır.

Yukarıdaki tartışmaya dayanarak, Kürtçe 'deki isim tamlaması için ortak bir c-yap1 kurallarını ele alacă̆ım.

${ }^{8}$ LK bağlaç anlamına gelir. Çalışmanın sonunda kullanılan kısaltmaların birbiriyle uyuşması için sınıflandırma hafifçe değiştirilmiştir. 


$$
\begin{aligned}
& \mathrm{N}^{\prime} \rightarrow \quad(\mathrm{N}) \quad(\mathrm{EZ} \quad \mathrm{DP}) \quad, \quad(\mathrm{EZ} \quad \mathrm{AP}) \\
& \uparrow=\downarrow \quad \uparrow=\downarrow \quad(\uparrow \text { POSS })=\downarrow(\downarrow \quad \uparrow=\downarrow \quad \downarrow \in(\uparrow \text { ADJ }) \\
& \mathrm{CASE})=\mathrm{OBL} \\
& \mathrm{NP} \rightarrow \quad\left(\mathrm{N}^{\prime}\right) \quad(\mathrm{EZ} \quad \mathrm{PP}) \\
& \uparrow=\downarrow \quad \uparrow=\downarrow \quad \downarrow \in(\uparrow \text { ADJ })
\end{aligned}
$$

Bu kurallar genel x-bar şemasına uyum sağlamıyor Bresnan (2001:chapter 6). İzafe morfeminin bastaki isimle uyum sağlayabilsin diye izafe morfemini dipnot birakmam bir nedendir. İkinci nedeni bir ismi niteleyen Sifat öbeklerin (APs) ve Edat öbeklerin (PPs) çoğunlukla niteleme sözcüklerine takılmalarına rağmen; Kürtçe'deki Chomsky'nin birleştirilmiş tarzını göstermemektedir. Örneğin; baştaki isim bu ifadelerle nitelendirildiğinde, daha ileri bir gösteri tasarlar. Bu, bir ismin çoğunlukla sadece bir Sıfat öbeğinin ve bir Edat öbeğiyle nitelendirileceğinin bir sonucudur. ${ }^{9}$

Böyle olağandışı kuralları düzenlemeyi seçmemin nedeni her ne zaman bir isim birden fazla bir sıfat öbeği ile nitelendirildiğinde, bu sıfat öbeklerin zorunlu olarak 've' gibi bir bağlaç kullanarak karışık bir sıfat öbeği ile birleşmek zorunda kalıyor gibi görünmesidir. Tek tek her biri beraberindeki izafe işaretiyle başlıklı bir isme eklenemezler. ${ }^{10}$

a. $\operatorname{mal}-a \quad \min =a$ house-EZ.FEM.SG 1.SG.OBL=EZ.FEM.SG

'my old, humid house'

' benim eski, nemli evim'

(Wurzel 1997:26)

b. * mal-a house-EZ.FEM.SG ev $\min =a$

1.SG.OBL=EZ.FEM.SG

benim

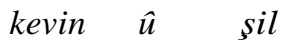

old and humid

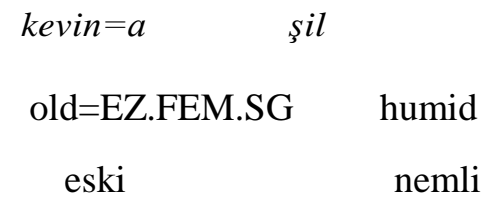

Şimdi birkaç tane sözcüksel kayıtlar vereceğim ve onları üç örnek isim tamlamasında analiz etmek için kullanacağım.

\footnotetext{
${ }^{9}$ Çeşitli Edat öbekleri mümkünse, uygun c-yapısı kuralı basitçe yansıtmalı olmayan olarak değiştirilmeli. Örneğin, tipik belirteç kuralı.

${ }^{10}$ Eğer farklı sıfat öbeklerin önadla bağlanması mümkünse( belki de farklı anlamlarla), daha standart bir belirteç kuralı önerilmelidir.
} 


\begin{tabular}{|c|c|c|c|c|c|}
\hline mal & $\mathrm{N}$ & $\begin{aligned}(\text { PRED }) & =\text { 'house' } \\
(\text { GEND }) & =\text { FEM }\end{aligned}$ & bira & $\mathrm{N}$ & $\begin{array}{l}(\text { PRED })=\text { 'brother' } \\
(\text { GEND })=\text { MASC }\end{array}$ \\
\hline$=(\mathrm{y}) \mathrm{a}$ & $\mathrm{EZ}$ & $(($ PRED $)=$ 'PRO' $)$ & $=(\mathrm{y}) \hat{\mathrm{e}}$ & $\mathrm{EZ}$ & $\left((\right.$ PRED $)=$ 'PRO' $\left.^{\prime}\right)$ \\
\hline $\min$ & $\mathrm{D}$ & $\begin{array}{l}(\text { GEND })=\text { FEM } \\
(\mathrm{NUM})=\mathrm{SG} \\
(\mathrm{DEF})=+ \\
(\mathrm{PRED})=\text { 'PRO'}\end{array}$ & picûk & A & $\begin{array}{l}(\text { GEND })=\text { MASC } \\
(\mathrm{NUM})=\mathrm{SG} \\
(\mathrm{DEF})=+ \\
(\mathrm{PRED})=\text { 'small' }\end{array}$ \\
\hline & & $\begin{array}{l}(\text { PERS })=1 \\
(\mathrm{NUM})=\mathrm{SG} \\
(\mathrm{CASE})=\mathrm{OBL}\end{array}$ & & & \\
\hline
\end{tabular}

Şimdi üç örnekte c-yapıları ve f-yapıları vereceğim.(15)

(15) a. mala birayê min a picûk

my brother's small house'

'kardeşimin küçük evi'

b. mala biray e min ê piaik

'my small brother's house'

'kü̧̈ük kardeşimin evi'

c. mala yê piçûk

'the small one's house'

'küçüğün evi'

Aşağdaki şekil (15a) için c-yapılarını göstermektedir. 


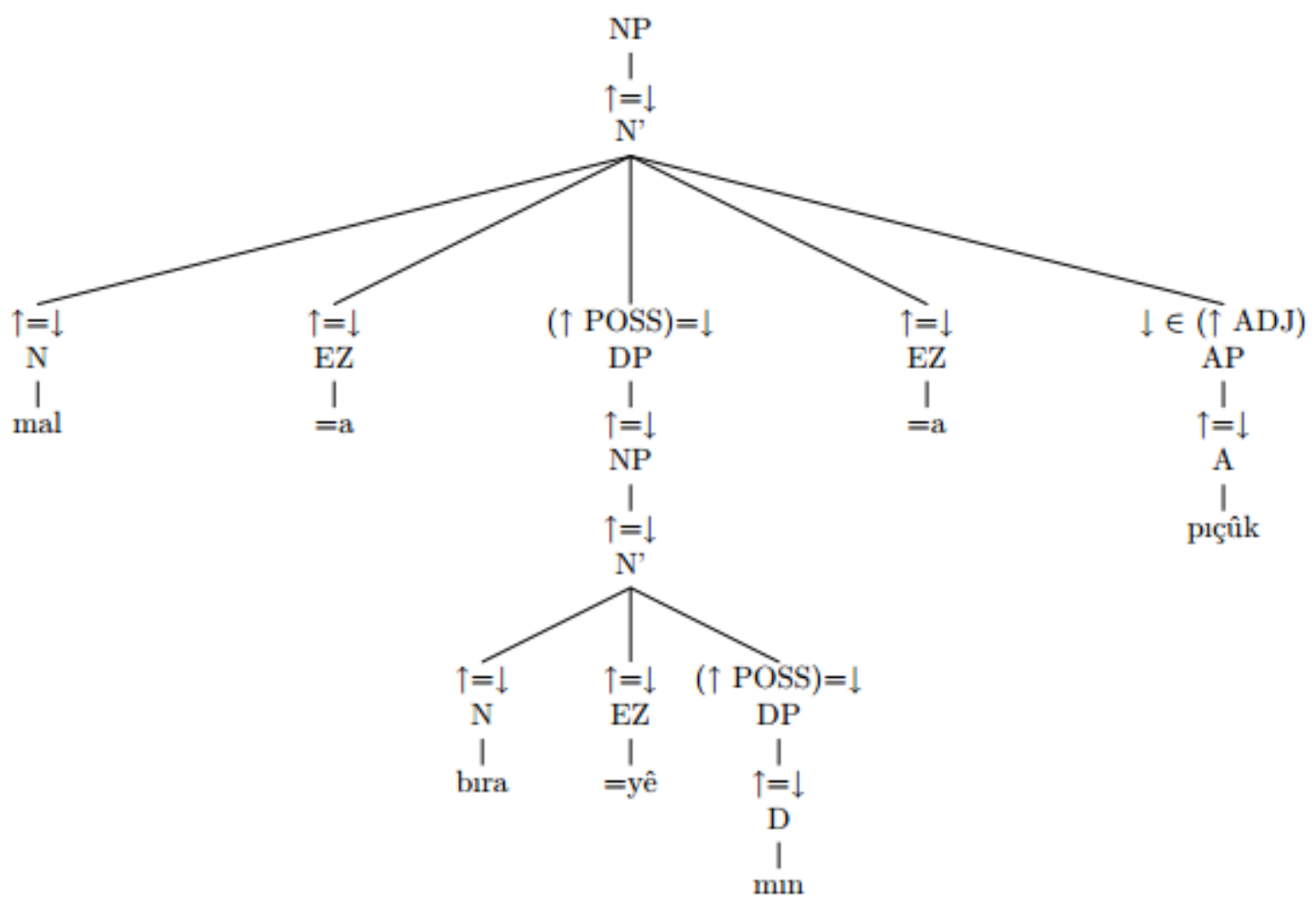

Elde edilen f-yapı (16) 'da gösterilmiştir.

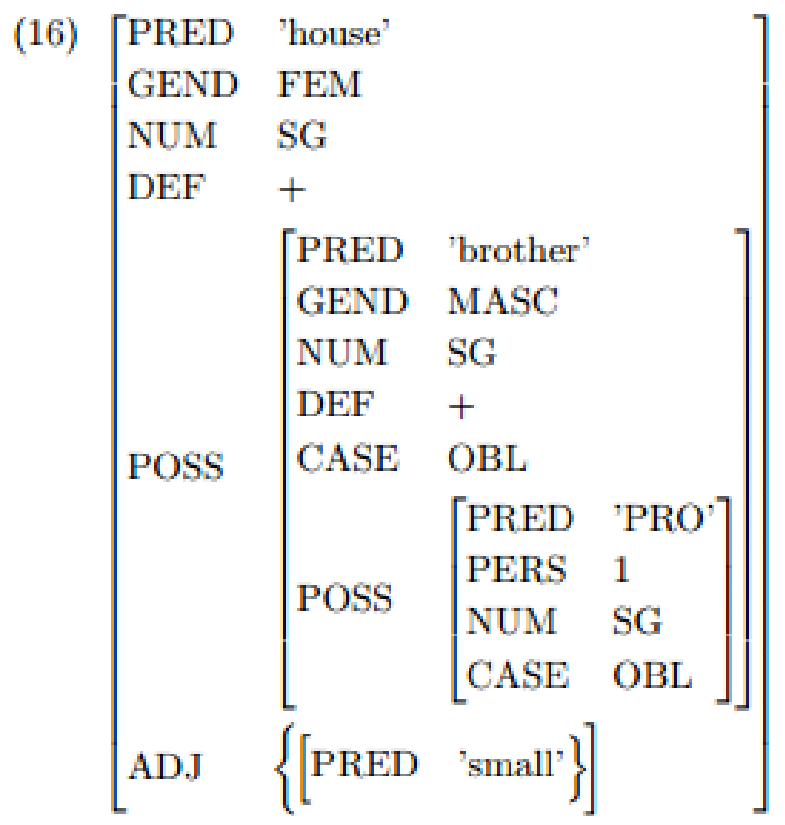


$\mathrm{Bu}$ örnektede görüldüğü gibi, izafe yapısı hangi ön adın çelişkili tamlayanı değiştirebilmesini kısıtlar. Bu cümlede, pi,ç̂ิk (small-küçük) sadece ilk isim olan mal (houseev) 'i değiştirebilir ve yapısal olarak mümkün olmasına rağmen bağlı olan bira (brother-kardeş ) kelimesini değiştiremez. Ayrıca izafe morfeminin seçmeli yüklemi f-yapının ön adıyla tam olarak bağlı değildir çünkü açık bir ön ad vardır ve böylece önceden bir yüklem bulunur. (15b) ye karşılık gelen yapılar aşağıda gösterilmiştir.

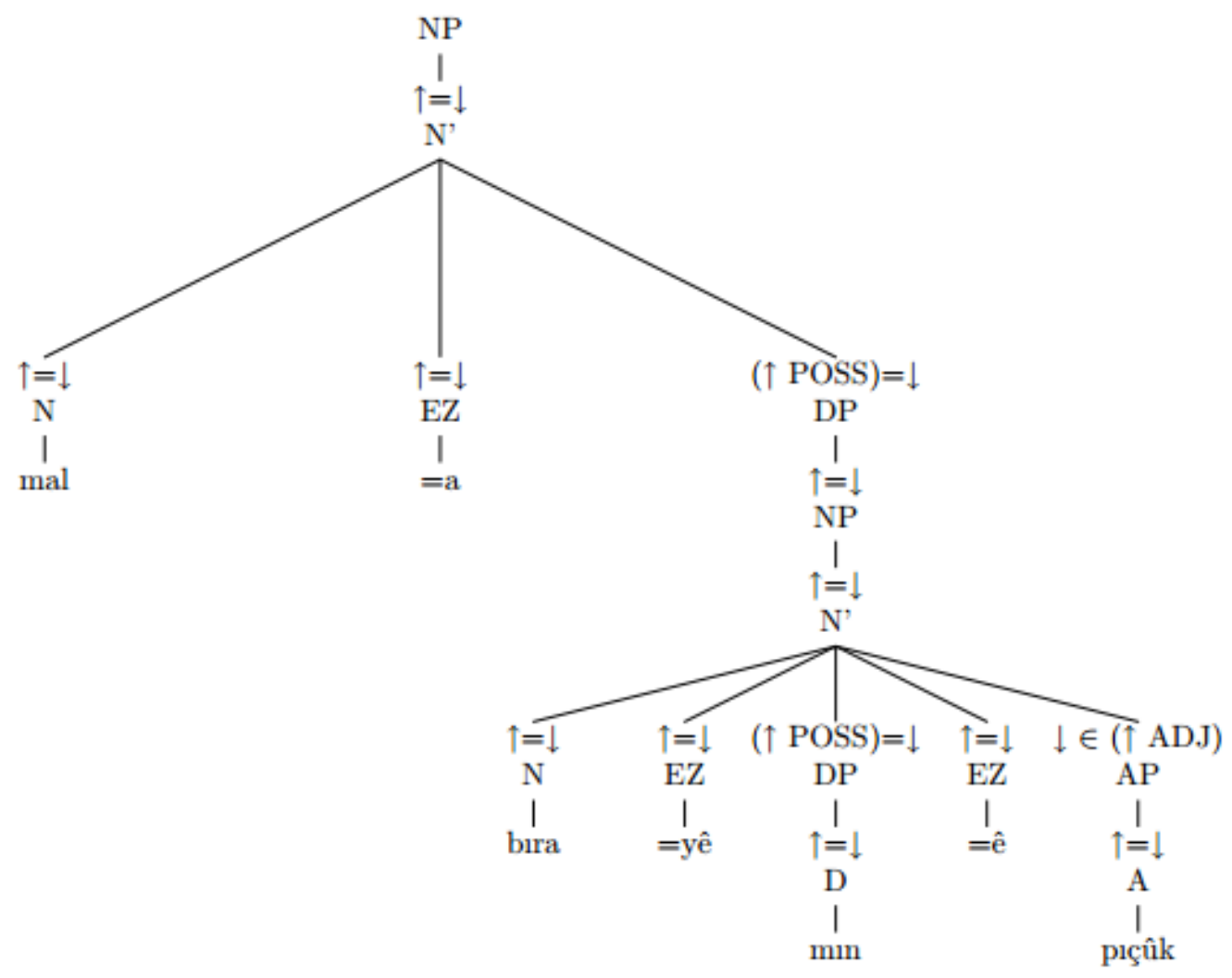

(17)

$\left[\begin{array}{llll}\text { PRED } & \text { 'house' } & & \\ \text { GEND } & \text { FEM } & & \\ \text { NUM } & \text { SG } & & \\ \text { DEF } & + & & \\ & {\left[\begin{array}{lll}\text { PRED } & \text { 'brother' } \\ \text { GEND } & \text { MASC } & \\ \text { NUM } & \text { SG } & \\ \text { DEF } & + & \\ \text { CASE } & \text { OBL } & \\ & {\left[\begin{array}{lll}\text { PRED } & \text { 'PRO' } \\ \text { PERS } & 1 \\ \text { NUM } & \text { SG } \\ \text { PASE } & \text { OBL }\end{array}\right]} \\ & \left\{\begin{array}{lll}\text { POSED } & \text { 'small' }\end{array}\right]\end{array}\right]}\end{array}\right]$


Bu örnekte, 'pi,çûk (küçük)' sıfatı sadece bağl1 olan 'bira (kardeş)' kelimesini değiştirebilir çünkü ondan önce gelen izafe işaretleyicisi mal ile değil bira ile uyuşur.

Sonuncusu ve önemlisi, son cümlenin analizi; önad olan 'mal' in iyelik eki olmayan bir sözcükle de değiştirilebileceğini gösterir.18'deki izafe işaretleyicisinin seçmeli yükleminde görüldüğü gibi baş iyelik eki için yüklem sağlar.

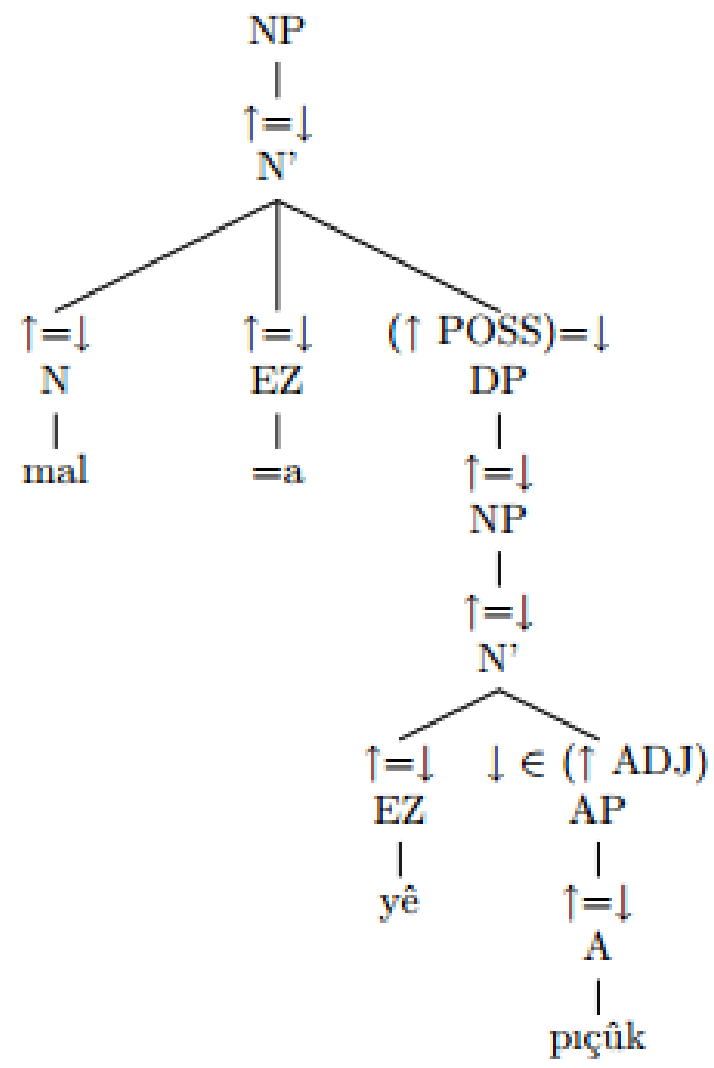

(18) $\left[\begin{array}{llll}\text { PRED } & \text { 'house' } & \\ \text { GEND } & \text { FEM } & & \\ \text { NUM } & \text { SG } & & \\ \text { DEF } & + & & \\ & \left.\left[\begin{array}{llll}\text { PRED } & \text { 'PRO' } & \\ & \text { GEND } & \text { MASC } & \\ \text { PUM } & \text { SG } & \text { DEF } & + \\ & \text { CASE } & \text { OBL } & \\ \text { ADJ } & \{[\text { PRED } & \text { 'small' }\}\end{array}\right]\right]\end{array}\right]$ 


\section{2 İkinci Modifiye Analiz}

Örneklerde, izafe işaretleyicilerini niteleyiciler üzerinde klitik olarak gördüm çünkü izafe işaretleyicisinin önad üzerinde gösterdiği durumdan hafif bir farklllık gösterirler. İzafe işaretleyicisinin önad üzerindeki morfofonolojik bütünleşme derecesi mükemmel görünüyor, izafe morfeminin kök değişimlerine neden olduğu örneği (19) inceleyiniz.
a. dê (mother-anne) + a (EZ.FEM.SG) $\rightarrow$ diya
b. rê (way- yol) + a (EZ.FEM.SG) $\rightarrow$ riya

$\mathrm{Bu}$ tür değişimler, izafe morfeminin niteleyicinin sağ kenarında klitik yaptığında meydana gelmemektedir. Örneğin;

(20)

$$
k e c ̧-a
$$

$t e=y a$

mezin

daughter-EZ.FEM.SG

2.SG.OBL=EZ.FEM.SG

big

'your big daughter'

'senin büyük kızın'

Ancak bu konuyu açıklığa kavuşturmak için daha fazla çalışma gerekir. Ön ad üzerinde izafe yi sonek olarak düşünmeye yönelik en iyi tartışma, Kurmanci izafesinin, isimdeki olası tüm çekim eklerini bastırmasıdır. 21a'da ki ' $m a l$ ' ismi olgu eki taşır çünkü gelen ek fiil tarafından dolaylıdır. 21b'de olduğu gibi isim sonraki bir öğe tarafindan nitelenirse, ek görünmez. Ancak tüm aitlik sıfatları halen dolaylı durumdadır çünkü işaret zamirleri ' $v i$ ' yapısında dolaylı görünmek zorundadır.

a. $e z$

[DP vi

mal-ê]

di-bîn-im

1.SG.NOM

DEM.SG.OBL

house-SG.OBL

DUR-see.PRES-1.SG

'I see this house.'

' Bu evi görüyorum'
b. $e z$
[DP vi
mal-a]
sor
di-bîn-im

1.SG.NOM DEM.SG.OBL ouse(ev)-EZ.FEM.SG red(kırmızı) DUR-see(görmek).PRES-1.SG

'I see this red house.'

'Bu kırmızı evi görüyorum' 

c. $* e z$
$[D P v i$
mal-a]
sor
di-bîn-im
1.SG.NOM DEM.SG.OBL house(ev)-EZ.FEM.SG red(kırmızı) DUR-see(görmek) .PRES-1.SG

Aynı birbirlerini niteleyen aitlik sıfatlarında görülür. Normalde sahiplik bildirenler dolaylı olarak görünmelidir ancak onlarda nitelendirildiğinde herhangi bir olgu morfemi taşımazlar. Onun yerine izafe ile gösterilmelidirler.

$$
\begin{aligned}
& \text { a. mal-a [NP jin-ê] } \\
& \text { House(ev) -EZ.FEM.SG woman(kadın)-SG.OBL } \\
& \text { 'the woman's house' ( Kadının evi) } \\
& \begin{array}{llll}
\text { b.mal-a } a \quad \text { jin- } a & \text { min }]
\end{array} \\
& \text { house-EZ.FEM.SG woman-EZ.FEM.SG 1.SG.OBL } \\
& \text { 'my wife's house' ( Eşimin evi) }
\end{aligned}
$$

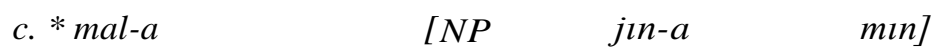

$$
\begin{aligned}
& \text { house-EZ.FEM.SG woman-EZ.FEM.SG 1.SG.OBL }
\end{aligned}
$$

$\mathrm{Bu}$ durumlar izafe morfeminin önad üzerinde artık bir klitik olmadığı ve bir çekim eki olduğunu gösterir. Bu yorumu daha iyi anlamak için, bu bölümde ikinci ve daha karışık bir analiz önerilecektir.

Önad üzerinde izafe morfem için revize bir analiz önerirken, iki niteleyici arasında görünen izafe morfemi için ilk klitik analizi sürdürülecektir. Ana problemler; isim nitelendirildiğinde sadece ismin izafe yapısının oluştuğunu nasıl emin olmak, izafe yapıdaki bir ismin başka bir izafe klitik yapılı isimi tarafından takip edilmediğinden nasıl kaçınılacağıdır.

Bir ismin izafe formu için aşağıdaki alt sözcük kuralını şöyledir:

$$
\mathrm{N}_{E Z} \rightarrow \begin{array}{cc}
\mathrm{N}_{\text {Stem }} \\
\uparrow=\downarrow & -\mathrm{EZ} \\
&
\end{array}
$$

İzafe ekinin sözcük girişi sonra aşağıdaki formu vardır. EZ.FEM.SG. için şöyle bir örnek sunulur: 
-ya $\quad-\mathrm{EZ} \quad(\uparrow \mathrm{GEND})=$ FEM

$(\uparrow \mathrm{NUM})=$

$\mathrm{SG}(\uparrow \mathrm{DEF})=+$

$(\uparrow \mathrm{ADJ}) V(\uparrow \mathrm{POSS})$

Son satır izafe yapıdaki bir ismin daima en az bir tamlayan ya da aitlik eki ile nitelendirilmesi zorunda olduğunu sağlar. Önad ile soldaki niteleyici arasındaki izafe işaretleyicisini ikileme probleminden kaçınmak direk değildir. Şu an ki analize dayanarak, izafe soneki taşıyan isimlerin niteleyici bir sözcük tarafından takip edilmesi Kürtçenin yapısal bir özelliği olduğunu varsaymak gerekmektedir. Birleştirmeyen özellik türlerini gerektiren bazı yapı ilkelerinden dolayı izafe işaretleyicisini ikileyen başka bir analiz hariçtir. Ancak, önad birden fazla niteleyici sözcük tarafindan takip edilirse, burada bu analizden dolayı çeşitli izafe işaretleyicileri aslında önadın f-yapısı ile birleşir. Bu seçenek burada geçerli değildir. İlave olarak, sadece Kürt izafe yapısı uğruna özel anlık bir sunuş tasarlamaktan kaçınmak gerekmektedir. ${ }^{11}$

Bununla birlikte, Kürtçe isim tamlaması için aşağıda düzenlenmiş yapı kuralları ${ }^{12}$ önerilmektedir.
a. $\quad \mathrm{N}^{\prime} \rightarrow \mathrm{N}_{E Z}$
$\uparrow=\downarrow$
b. N' $\rightarrow \quad \mathrm{N}_{E Z}$
$\uparrow=\downarrow$
c. $\mathrm{NP} \rightarrow \mathrm{N}_{E Z}$
$\uparrow=\downarrow$
d. N' $\rightarrow \quad$ (N')$$
\uparrow=
$$
e. $\mathrm{N}^{\prime} \rightarrow \quad$ (N')$$
\uparrow=\downarrow
$$
f. $\quad \mathrm{NP} \rightarrow \quad\left(\mathrm{N}^{\prime}\right)$

$$
\uparrow=\downarrow
$$
g. NP $\rightarrow \quad \mathrm{N}$
h. NP $\rightarrow \quad \begin{aligned} & \uparrow= \\ & N^{\prime}\end{aligned}$
DP
$(\uparrow$ POSS $)=\downarrow(\downarrow$
$\mathrm{CASE})=\mathrm{OBL}$
AP
$\downarrow \in(\uparrow \mathrm{ADJ})$
$\mathrm{PP}$
$\downarrow \in(\uparrow \mathrm{ADJ})$
(EZ
DP)
$\uparrow=$
$(\uparrow \mathrm{POSS})=$
$(\downarrow \mathrm{CASE})=\mathrm{OBL}$
(EZ
$\uparrow=\downarrow$
AP)
$\neg(\uparrow \mathrm{ADJ}) \Rightarrow \downarrow \in(\uparrow \mathrm{ADJ})$
(EZ
$\uparrow=\downarrow$
$\mathrm{PP})$
$\downarrow \in(\uparrow \mathrm{ADJ})$

\footnotetext{
${ }^{11}$ Ancak biri ekonomi ilkesinin bazı sürümlerini kullanabilir. Sadler 1997.

${ }^{12} \mathrm{Kural}$, (d) öncül aitlik sözcüklerin, sadece öncül aitlik sözcük özelliklerine sahip olmayan aitlik sözcüklerine izin vererek başka niteleyiciler tarafından önad ile ayrılmış şekilde oluşmayacağını kesinleştirmelidir.
} 
(g) karmaşık ad cümlelerindeki önadın daima izafe işaretli olmasını sağlayan izafe sonekini taşımayan ad' a izin veren tek kuraldır. İki seviyeli yapı ayrılabilinir; (a-c) kuralları önadın en soldaki niteleyicileri için farklı olasılıklar sağlar. Tüm ileriki değişiklikler (d-f) kuralları ile uyuşmak zorundadır. (e) kuralındaki sıfat cümleciklerindeki (AP) $\neg(\uparrow$ ADJ) $\Rightarrow \downarrow \epsilon$ $(\uparrow \mathrm{ADJ})$ dipnotu farklı sıfat cümleciklerindeki değişikliklerde gereklidir. Bu ekstra durum aitlik kelimeleri için geçerli değildir. Teklik koşulu yerine getirilmek zorunda kalsın diye, isim cümleciğinin özne ile karşılaştırılmasında aitlik sözcüğü bir gramer fonksiyonu değildir (cf. Sadler 1998 and Bresnan 2001:47).

Şimdi, bu değiştirilmiş kuralları $15^{\prime}$ 'deki isim cümleciklerindeki üç örneğe uyarlanacaktır. Öncelikle 15-a için c-yapısı gösterilecektir. Karşılık gelen F-yapısı (16) 'daki ile aynıdır.

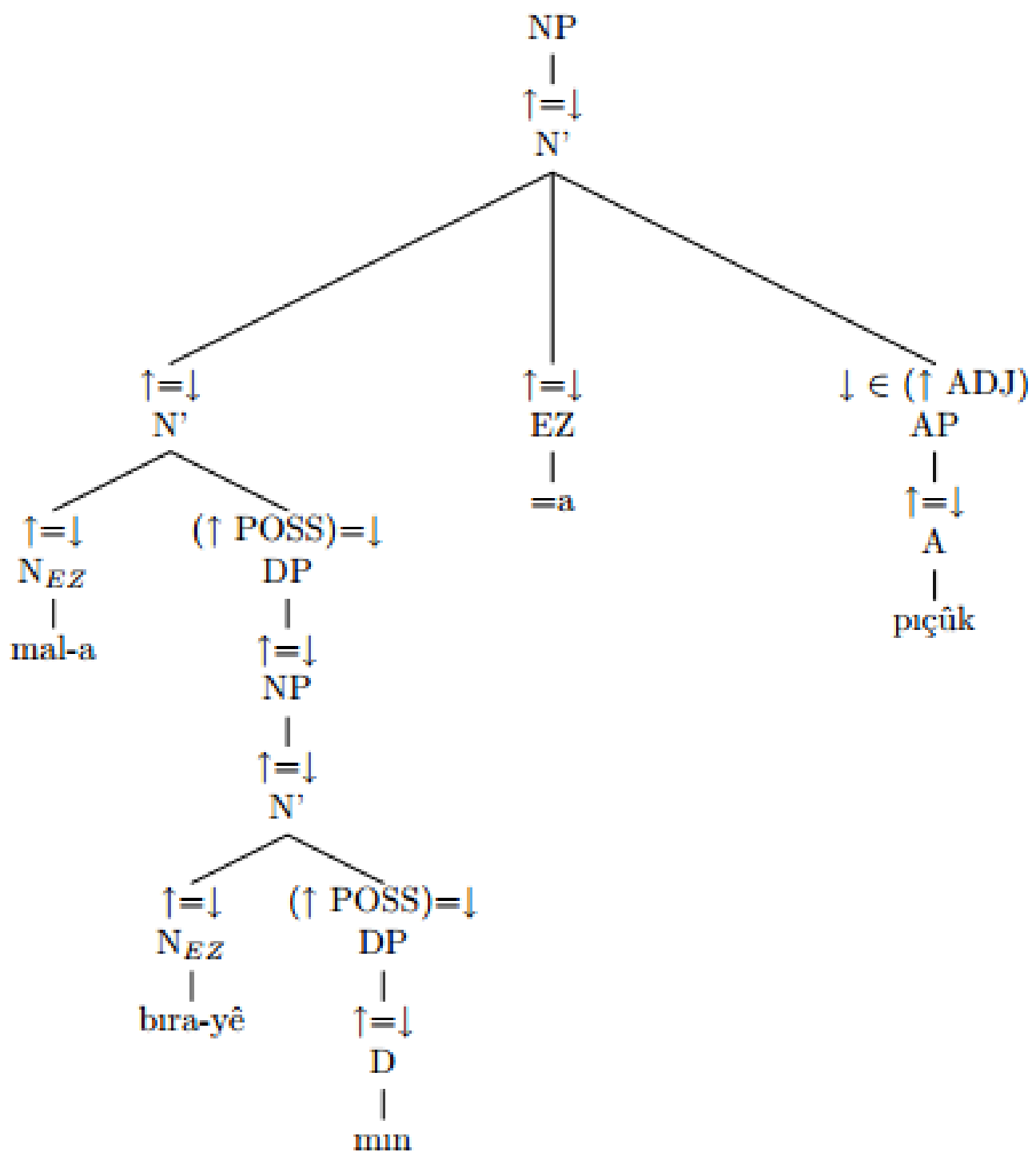


Karşılık gelen f-yapı (17)'deki ile tekrar aynı iken, c-yapısı (15b) örneği şu şekildedir:

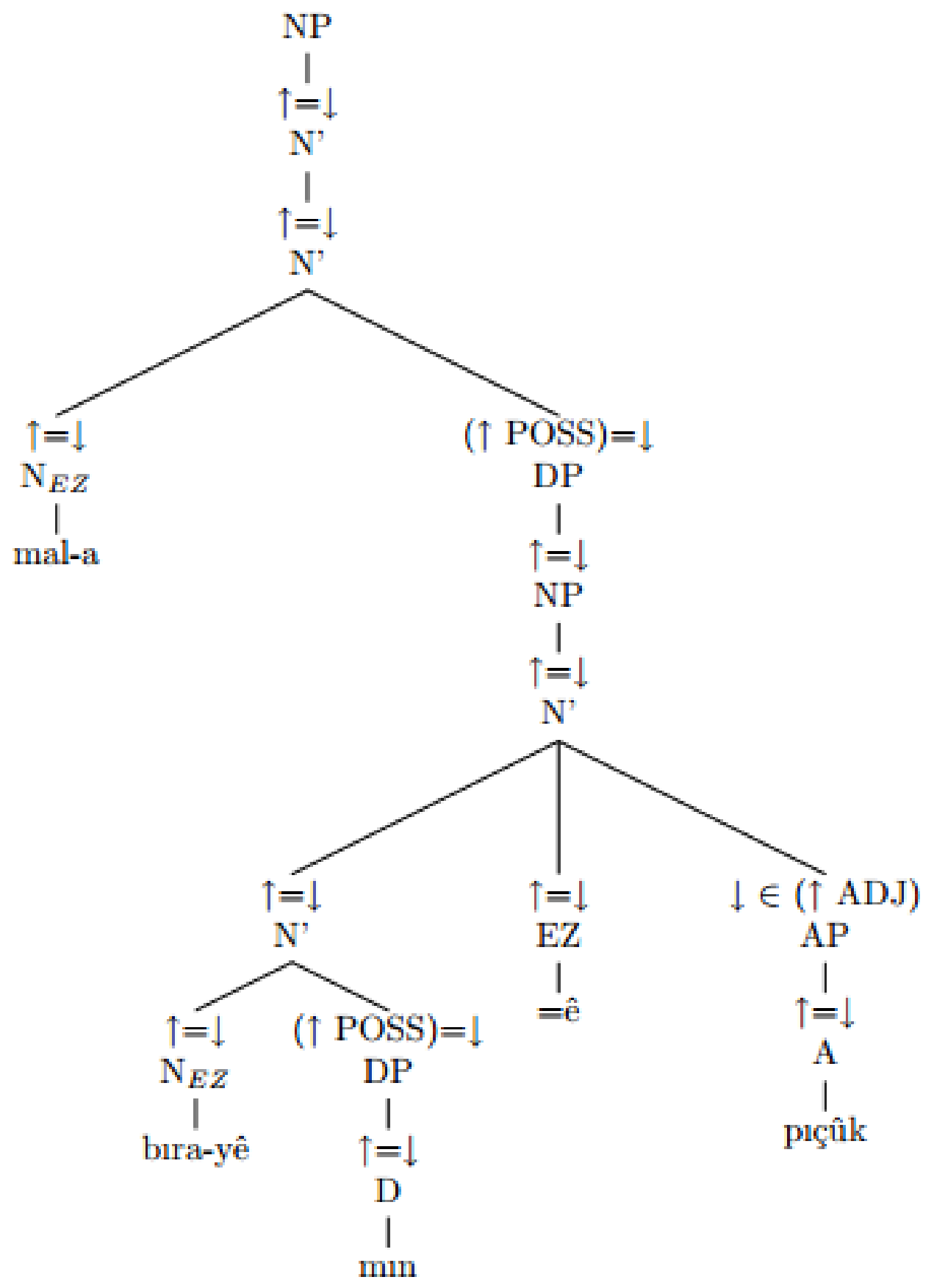

En son ve önemli olan, (15c) de değiştirilmiş kurallarla analiz edilebilinir. Tekrar karşılık gelen f-yapı (18)'deki ile aynıdır. 


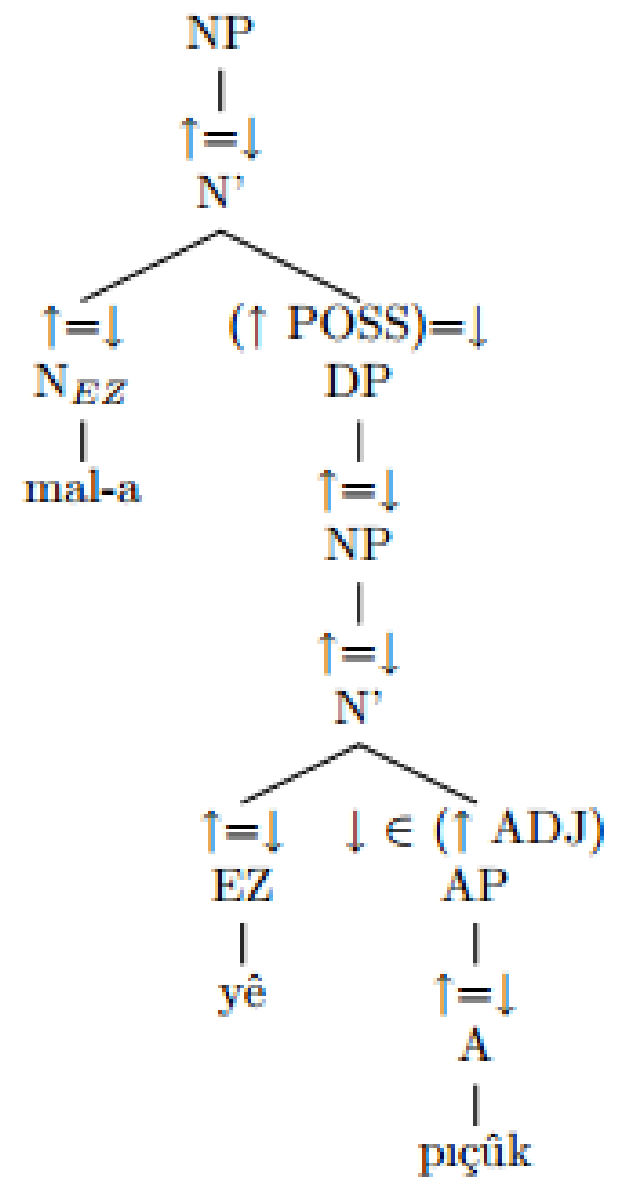

\subsection{Durum ve İafe Arasındaki İlişki}

Her iki analiz (4.1 ve 4.2) altında, önad değiştirildiğinde, durumun artık önad üzerinde işaretlenmediği gerçeği hesaba katılmak zorundadır. Bu bölüm 4,2 analizi için basittir. İzafe eki taşıyan bir ismin kendisi tarafından hiçbir durumda özelliği olmadığ varsayılabilir. Ancak bir fiil ya da iyelik eki gibi bir yapı tarafından halen de bir durum olarak görünebilinir. Değişmemiş adlar; eğer durum eki taşıyorsa DOLAYLI ya da durum işaretleyicisi taşımıyorsa YALIN olarak izafe eki olmayan adları özelleştirip ya yalın ya da dolaylı doğru bir durum yapısında görünmek zorundadırlar. Bölüm 4.1 deki ilk analizden, sorunun çözümü daha az kolaydır. İzafe morfeminin DP (aitlik sözcükleri) 'den dolayı $\neg \uparrow$ CASE) gibi bir sözcük bilgisini taşıdığı basitçe ifade edilemez ve böylece de önadlar; fiiller, edatlar ve belirli yapılar tarafından durum olarak gösterilebilinir. Bu durum, eğer değiştirilmişse önad ile birlikte ifade edilemez ancak örnek olarak niteleyici sözcük üzerinde belirteç rolü alır. Tüm izafe işaretleyicilerinin; durum işaretleyicisi ve değişim ilişkisini benimseyen klitiklerin olduğunu öne süren ilk analiz ile ilgili soru açık birakılacaktır. 


\section{EK ÇALIŞMALAR}

Kürt dili izafesi ile ilgili ek çalışmalar, Kürtçe isim tamlaması ile ilgili önemli bir dizi soruya açıklık getirir. Verilen bir önadın sadece bir sıfat tamlaması ya da sadece bir edat tamlaması tarafından değiştirileceğinin gerçekten de durum olup olmadığının örneği araştırmalıdır. İlaveten, birinin Kürtçe 'deki bir ismin yardımcı ve tamamlayıcı öğelerini ve bu öğeler arasındaki hangi sözdizimsel farklılıklarının bu ayrımın belirtileri olduğunu ayırt edip edemeyeceği henüz net değildir. Bu çalışmada önemsenmeyen bazı ileri düzeydeki karışık durumlar daha detaylı incelenmelidir. Öncelikle, Kürtçe'nin bazı lehçelerinde belirli ve belirsiz izafe belirteçleri arasında bir ayrım vardır; ancak diğerleri, örneğin Türk lehçesi belirtisiz izafeyi tamamen kaybettiği görünüyor. İkincisi, bir ad ya da ad tamlaması için olan durum ve kurallar incelenmelidir. 23. örnek, tüm yapının değişmesine rağmen bağlantılı cümledeki sonad sadece izafe ekinin hangi adla görüneceğini belirler.

\begin{tabular}{|c|c|c|c|}
\hline 23. Mizgîn & $l i$ & sûna di-ya & li $\quad$ [xwiş $\quad \hat{u}$ \\
\hline Mizgin & Instead & mother-EZ.FEM.SG & on sister and \\
\hline Mizgin & yerine & annesinin & (belirteç) e kızkardeş ve \\
\hline \multicolumn{2}{|c|}{ bir- $-\hat{\boldsymbol{e}}]$} & xwe & di-nêr-e. \\
\hline \multicolumn{2}{|c|}{ brother-EZ.M.SG } & REFL & DUR-watch.PRES-2/3.SG \\
\hline & ardeş & (belirteç) & (bakmak) \\
\hline
\end{tabular}

'Mizgin cares for her sisters and brother in her mother's stead.' (Wurzel 1997:63)

( Mizgin, annesinin yerine kız kardeşlerine ve erkek kardeşine bakar.)

Mizgin'nin sadece birkaç kız kardeşi ve bir erkek kardeşi olduğu yukarıdaki bağlamdan açık olmasına rağmen, bağlamdaki sonad 'da görünen izafe, 23.örnekte kendini tekil eril yapan ad tarafından belirlenir. Ancak 24. örnek, önceki ek bir değiştiriciyle klitik izafe işaretleyicisinin tüm değiştirilmiş isim tamlamasıyla uyuşmasını ve böylece çoğul yapıda göründügünü gösterir.

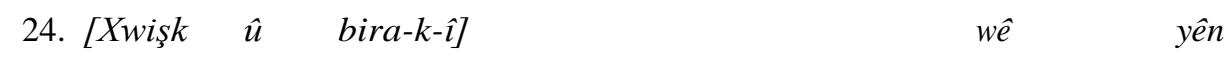

Sister and brother-INDEF-EZ.MASC.SG.INDEF 3.SG.FEM.OBL EZ.PL

Kızkardeş ve erkekkardeş ( belirtisiz eril) (tekil dişil) biz( çoğul) 


$\begin{array}{cc}\text { picûk } & \text { he-ne. } \\ \text { small } & \text { exist-PL. } \\ \text { (küçük) } & \text { var-( çoğul) }\end{array}$

'She has little sisters and a little brother.' (Wurzel 1997:63)

' Küçük kız kardeşleri ve bir erkek kardeşi var.'

Sonuncusu ve en önemlisi, Farsçada hafifçe farkl1lık gösteren Fars izafesi ile Kürt izafesini karşılaştırmak oldukça ilginç olabilir. Şu an ki çalışma önerisi ile karşılaştırılabilinecek (Kahnemuyipour 2000 gibi) Farsça yapısının analizi ile ilgili birkaç tane öneri olmuştur.

\section{SONUÇ}

$\mathrm{Bu}$ çalışmada yapılan analizler, LFG teorisinin söz dizimselinde, Kürtçe sözdizimindeki isim tamlamalarını açıklayan ilk çalışmalardan sadece biri olmasına rağmen; bu çalışmanın hem ne kadar zor hem de o ne kadar büyüleyici olduğunu gösterir. Kürt izafenin resmi söz dizimlerdeki teorilerin yeterli ilgi görmemesi gibi “yapıları birleştirme' benim ilk izlenimimdir. Olayın kendisi o kadar nadir değildir. İlgili yapılar Tagalog ${ }^{13}$ gibi birçok farklı diller ve dil ailelerinde görünür ( Himmelmann 1997). Bu yüzden LFG gibi resmi bir teorinin bu durum için seçkin analizler sunup sunmayacağı ya da bir tüm yeni yapı çeşidinin var olan sözdizimsel teorileriyle birleştirilip birleştirilmeyeceğini görmek verimli bir çalışma olmalıdır.

\section{TERİMLER:}

DP Aitlik öbeği / iyelik eki

PP Edat öbeği

NP I I Isim tamlaması / Ad öbeği /

PRED $\quad$ Yükim cün

${ }^{13}$ Filipinlerin resmi dili 


$\begin{array}{llll}\text { CASE } & \text { Durum } & \text { MAS } & \text { Eril } \\ \text { OBL } & \text { Nesne } & \text { DEM.SIG.OBL } & \begin{array}{l}\text { Belirtili Tekil } \\ \text { Nesne }\end{array} \\ \text { Adjunct } & \text { Belirteç } & \text { 1.SG.OBL } & \text { 1.Tekil Şahıs } \\ \text { Complement } & \text { Tamlayan } & \text { MASC. SG } & \text { Eril Tekil Şahıs } \\ \text { Num } & \text { Sayı } & \text { Fem. SG } & \text { Dişil Tekil } \\ \text { SG } & \text { Tekil } & \text { Qnt } & \text { Miktar/Sayı } \\ \text { PL } & \text { Çoğul } & \text { Prn } & \text { Zamir } \\ \text { AP } & \text { Sifat Öbeği } & \text { POSS } & \text { Aitlik } \\ \text { EZ } & \text { İzafe } & \text { GEND } & \text { Cinsiyet } \\ \text { Clitics } & \text { Klitik } & \text { MAS } & \text { Eril } \\ \text { FEM } & \text { Dişil } & \text { DEM.SIG.OBL } & \text { Belirtili Tekil } \\ & & & \text { Nesne }\end{array}$

\section{KAYNAKÇA}

Bresnan, Joan (2001): Lexical-Functional Syntax. Blackwell Textbooks in Linguistics 16. Blackwell Publishers, Malden, Massachusetts.

Himmelmann, Nikolaus P. (1997): Deiktikon, Artikel, Nominalphrase: zur Emergenz syntaktischer Struktur. Max Niemeyer Verlag, Tübingen.

Kahnemuyipour, Arsalan (2000): Persian Ezafe Construction Revisited: Evidence for Mod- ifier Phrase. In: Proceedings of the 2000 annual conference of the Canadian Linguistic Association, pp. 173-185.

MacKenzie, D. N. (1961): Kurdish Dialect Studies I. Oxford University Press, London. Sadler, Louisa (1997): English Auxiliaries as Tense Inflections.

Online: citeseer.nj.nec.com/sadler97english.html.

Sadler, Louisa (1998): Welsh NPs without Head Movement. In: Proceedings of the LFG98 Conference, University of Queensland, Brisbane. CSLI publications.

Online: http://www-csli.stanford.edu/publications/

Wurzel, Petra (1997): Rojba,s. Einführung in die kurdische Sprache. Sprachenreihe Re- ichert. Dr. Ludwig Reichert Verlag, Wiesbaden. 